\title{
Apoyo social y tipología familiar en mujeres diagnosticadas con VIH
}

\author{
Social support and family typology in women diagnosed with HIV
}

Apoio social e tipologia familiar em mulheres com diagnóstico de HIV

\author{
Esther Patricia Polo Payares'; Adriana Azucena Ardila Hernández²; Dannis Daniela Ibáñez Polo³ \\ 1 Enfermera. Mg. en Estudios de Género, Área Mujer y Desarrollo. Universidad de Cartagena. epolop@unicartagena.edu.co. ORCID: \\ https://orcid.org/0000-0001-8691-7976. \\ 2 Enfermera. Universidad de Cartagena. adrianaardila95@gmail.com. ORCID: https://orcid.org/0000-0002-5359-9438. \\ 3 Enfermera. Universidad de Cartagena. danibapol@outlook.com. https://orcid.org/0000-0002-6483-7059.
}

Recibido: 03/12/2019. Aprobado: 18/12/2020. Publicado: 28/01/2021

Polo-Payares EP, Ardila Hernández AA, Ibáñez-Polo DD. Apoyo social y tipología familiar en mujeres diagnosticadas con vih. Rev. Fac. Nac. Salud Pública. 2021;39(1):e340517. DOI: https://doi.org/10.17533/udea.rfnsp.e340517

\section{Resumen}

Objetivos: Determinar la relación entre el apoyo social y la tipología familiar según cohabitación en misma vivienda, en mujeres que conviven con virus de inmunodeficiencia humana/síndrome de inmunodeficiencia adquirida, usuarias de una institución prestadora de servicios de salud en Cartagena. Método: Estudio transversal analítico, realizado entre mayo y junio del 2018, con mujeres mayores de 18 años que manifiestan dicha condición. La muestra fue de 100 participantes, seleccionadas mediante un muestreo aleatorio simple. Se utilizó el "Estudio de desenlaces médicos de apoyo social", para la evaluación del apoyo social percibido; la "Ficha sociodemográfica", para la caracterización social, y la "Encuesta nacional de demografía y salud", para la tipología familiar según convivencia. Resultados: La edad promedio de las participantes fue de 40 años. La tipología familiar tuvo una distribución casi homogénea: del $27 \%$ la nuclear incompleta extensa, $22 \%$ la nuclear completa y con un $23 \%$ la nuclear incompleta; el índice global de apoyo social fue de $83 \%$; las participantes percibieron un apoyo social máximo. El índice global de apoyo social respecto a los tipos de familia arrojó un puntaje máximo, esto es, entre 74,5 y 101,2. Y la relación entre el índice global de apoyo social y la tipología familiar según convivencia no mostró una diferencia significativa, con 0,087 . Conclusiones: Los resultados de este estudio indican que las mujeres que padecen la enfermedad perciben un buen apoyo social en relación con sus tipologías familiares.

--Palabras clave: Apoyo social, VIH, sida, mujeres, composición familiar. 


\begin{abstract}
Objectives: to determine the relationship between social support and family typology according to coexistence in women who live with Human Immunodeficiency Virus/ Acquired Immunodeficiency syndrome users of an Institution Provider of Health Services in Cartagena. Methods: analytical cross-sectional study with a population of women with Human Immunodeficiency Virus/ Acquired Immunodeficiency syndrome users of an Institution Provider of Health Services in Cartagena, Colombia between May and June 2018. The sample was of 100 participants selected through simple aleatory sampling. As a technique of data gathering were used, Medical Outcomes Study - Social Support Survey for the evaluation of perceived social support, the sociodemographic record for social characterization and the National Demographic and Health Survey for the family typology according to
\end{abstract}

coexistence. Results: The average age of the women were 40 years. The family typology had an almost homogeneous distribution, between $27 \%$ the incomplete nuclear extensive, $22 \%$ the complete nuclear and with $23 \%$ the incomplete nuclear one; the global index of social support, $83 \%$ of the participants perceived maximum social support. The overall index of social support against family types gave a maximum score, that is, between 74.5 and 101.2. The relationship between social support and family typology according to coexistence did not show a significant difference with 0,087 . Conclusions: the results of this study indicate that women with HIV perceive a good social support in relation to family typology.

-Keywords: Social support, perception, HIV, women, family characteristics.

\section{Resumo}

Objetivos: Determinar a relação entre o suporte social e a tipologia familiar segundo coabitação no mesmo domicílio, em mulheres portadoras do vírus da imunodeficiência humana / síndrome da imunodeficiência adquirida usuárias de uma instituição prestadora de serviços de saúde em Cartagena. Método: estudo transversal analítico, realizado entre maio e junho de 2018, com mulheres maiores de 18 anos que manifestam essa afecção. A amostra foi composta por 100 participantes, selecionados por amostragem aleatória simples. O "Estudo dos resultados médicos do apoio social" foi usado para avaliar o apoio social percebido; o "Arquivo Sociodemográfico", para a caracterização social, e a "Pesquisa Nacional de Demografia e Saúde", para a tipologia familiar por convivência. Resultados: a idade média dos participantes foi de 40 anos. A tipologia familiar teve uma distribuição quase homogênea: $27 \%$ nuclear extenso incompleto, $22 \%$ nuclear completo e $23 \%$ nuclear incompleto; o índice global de apoio social foi de $83 \%$; os participantes perceberam o máximo apoio social. O índice global de suporte social com relação aos tipos de famílias obteve pontuação máxima, ou seja, entre 74,5 e 101,2. E a relação entre o índice global de suporte social e o tipo de família de acordo com a convivência não apresentou diferença significativa, com 0,087. Conclusões: Os resultados deste estudo indicam que as mulheres que sofrem com a doença percebem um bom suporte social em relação às tipologias familiares.

-------- Palavras-chave: Apoio social, HIV, AIDS, mulheres, composição familiar

\section{Introducción}

En Colombia, para el año 2018, alrededor de 160000 personas se diagnosticaron con virus de inmunodeficiencia humana (VIH), de las cuales 31 mil eran mujeres mayores de 15 años [1]. En Cartagena, según registros del Sistema Nacional de Vigilancia en Salud Pública, hasta la semana epidemiológica 52 del año 2017 se notificaron 517 casos de VIH y muerte por síndrome de inmunodeficiencia adquirida (SIDA), de los cuales 145 (28\%) eran mujeres [2].

El VIH sigue siendo un problema de salud pública, por el progresivo aumento de casos, sus altas tasas de morbimortalidad y la falta de adherencia al tratamiento, que afecta a toda la población a nivel mundial, sin distinción alguna de sexo, edad, raza o procedencia. En Colombia, el VIH se encuentra en la lista del Fondo Co- lombiano de Enfermedades de Alto Costo del Ministerio de Salud y Protección Social y el Ministerio de Hacienda y Crédito Público [3].

En la perspectiva psicológica, algunos autores, como Moral y Segovia, plantean que "al trasmitirse el rumor de que una persona es seropositiva, sufre estigma y discriminación, y tiene como consecuencia aislamiento, ira, depresión y más hospitalizaciones. Este rechazo social afecta de manera negativa en ambos sexos, pero en las mujeres tienen mayor impacto por su mayor dependencia de campo ${ }^{*}$ y vulnerabilidad interpersonal" $[4$, p. 205]. Es importante destacar que las mujeres portadoras de VIH, en comparación a los hombres con esta condición, son más vulnerables a manifestar más síntomas de ansiedad y depresión [5].

* Son personas dependientes del contexto social y tienden a ser emocionales (Nota de las autoras). 
Por otro lado, respecto a los roles tradicionales de género, la subordinación de la mujer la ha expuesto a una situación de vulnerabilidad ante la epidemia del viH, y cuando ello ocurre, son objeto de discriminación por ser mujeres y tener $\mathrm{VIH}$, junto a los distintos componentes presentes en la construcción de su identidad, como el origen étnico, la condición social, el nivel educativo, entre otros, que pueden llegar a configurar una discriminación múltiple [6]. Un aspecto relevante a tener en cuenta es que, además de convivir con VIH, las mujeres tienen posibilidad de mayor sufrimiento e inestabilidad en el manejo de situaciones como abusos al interior de sus familias, violencias, abandono de la pareja, entre otras [7]. La experiencia de vivir con VIH pudiese también ser distinta entre mujeres según su dependencia económica y el acceso y la calidad de los servicios de salud.

Ahora bien, el apoyo social que provee interacción, suplencia de necesidades materiales, sostén emocional y social influye positivamente en la salud [8]. Un trabajo realizado en Colombia muestra que las personas que conviven con VIH que reciben apoyo social, incrementan su calidad de vida [9].

Es importante entender que la familia es la primera red de apoyo social que tienen las personas, al ser un espacio de protección y ayuda; sin embargo, también puede difundir información o conductas negativas, y en lugar de ser un apoyo, propicia riesgos a la salud, como lo demostró una investigación efectuada en Colombia, la cual concluyó que existen diferentes reacciones de la familia frente a la enfermedad, que puede ser, en algunos casos, el apoyo afectivo, abnegado y solidario, o presentar limitaciones y distanciamiento por razones laborales o de interacción personal con la persona enferma [10].

En Cartagena, Colombia, poco se ha investigado sobre este tema, de manera que este estudio busca resolver el interrogante sobre cuál es la relación entre el nivel de apoyo social y la tipología familiar de mujeres mayores de 18 años que conviven con VIH/SIDA usuarias de una institución prestadora de salud (IPS) en la ciudad, y así poder brindar herramientas para un abordaje integral, facilitando el proceso de su enfermedad.

\section{Metodología}

Esta es una investigación transversal analítica, realizada en una IPS que atiende pacientes con diagnóstico de VIH. La población estuvo conformada por 253 de mujeres, de las cuales 136 cumplían los criterios de inclusión.

Se utilizó una fórmula para muestra finita, con un nivel de confianza del $95 \%$ y un error de $5 \%$, dando un tamaño muestral total de 100 mujeres, a quienes se les aplicaron los instrumentos.

El muestreo fue aleatorio simple, tomando como referencia la agenda de citas planeadas para tres meses, donde se podría abordar a cada paciente en alguna de las consultas integrales (médica, enfermería, farmacia, trabajo social).

Las pacientes eran interrogadas por el personal institucional, para conocer si querían participar; una vez asentían, eran remitidas a un consultorio privado y cómodo, asignado por la institución, donde se les explicaba el objetivo de la investigación, los componentes éticos de la misma y se les pedía firmar el consentimiento, preservando siempre la confidencialidad de la información y la identidad de las usuarias.

Se aplicaron tres instrumentos:

- Ficha sociodemográfica: permitió la caracterización social de las participantes.

- Estudio de desenlaces médicos de apoyo social (Cuestionario mos - Medical Outcomes Study-): mide el apoyo social percibido. Es un cuestionario breve y autoadministrado, dirigido a personas mayores de 18 años. El instrumento evalúa los siguientes componentes: 1) apoyo emocional, 2) apoyo instrumental/material, 3) interacción social positiva - también llamado "relaciones sociales de ocio y distracción"- y 4) apoyo afectivo.

Este cuestionario permite valorar multidimensionalmente el apoyo social y detecta situaciones de riesgo social; en Colombia fue validado por Londoño et al. en el año 2012 mostró un alfa de Cronbach entre 0,921 y $0,736[11]$.

- Instrumento para tipología familiar según convivencia: tomado del "Apéndice A. Cuestionario de hogar" de la "Encuesta nacional de demografía y salud". Este instrumento permitió dimensionar el número de personas que habitan en la casa con la participante e identificar su relación de parentesco. La información fue procesada y analizada con el paquete estadístico SPSS ${ }^{\mathbb{R}}$ versión 16.0 (Estados Unidos, 2008). Se utilizó la prueba no paramétrica de KruskalWallis, para comparar los puntajes promedios de las diferentes dimensiones del apoyo social según la tipología familiar y se explicaron las variables que tuvieron una significancia menor de 0,05 . Se efectuó el resumen de prueba normal de Kolmogorov-Smirnov de los diferentes tipos de familias de mujeres, para la distribución de diferencias extremas. Asimismo, se hizo el análisis de varianza (ANOVA) y la prueba post hoc Tukey al interior de la dimensión "apoyo emocional".

La presente investigación tuvo en cuenta la Resolución 008430 del Ministerio de Salud de Colombia [12] y los principios de ética de la enfermería para Colombia [13] con el fin de salvaguardar la dignidad y la privacidad de las mujeres partícipes durante el estudio, respetando sus decisiones, creencias, patrones culturales y de conocimientos en torno a los temas a abordar en él. Revisados estos lineamientos, se obtuvo el aval del Co- 
mité de Investigación de la Facultad de Enfermería de la Universidad de Cartagena.

\section{Resultados}

A continuación se presentan las características sociales y demográficas de las participantes, su distribución en los tipos de familias con las que conviven, sus percepciones del apoyo social que reciben según las dimensiones - apoyo emocional, apoyo instrumental/material, interacción social positiva y apoyo afectivo-, seguido de las relaciones de significancias entre el apoyo social percibido y las tipologías de familia según convivencia.

\section{Características sociodemográficas}

El grupo objeto de estudio estuvo conformado por $100 \mathrm{mu}-$ jeres, con una edad promedio de 40 años, siendo 18 la edad mínima y 67 años la máxima, con una desviación estándar de 11,83 , procedentes en un $80 \%$ de la zona urbana.
En relación con la escolaridad, solo el $2 \%$ de la población tiene estudios profesionales, el $1 \%$ es analfabeta y el $37 \%$ cursó hasta la secundaria incompleta (véase Tabla 1). Referente al régimen de salud (el cual indica la categoría de afiliación al sistema de salud del país), el $98 \%$ se encuentra afiliado al subsidiado. En lo que atañe al estrato socioeconómico, que alude a la clasificación en niveles sociales de la población de acuerdo con su capacidad adquisitiva de vivienda: "los estratos socioeconómicos en los que se pueden clasificar las viviendas y/o los predios son 6, denominados:1. Bajo-bajo 2. Bajo 3. Medio-bajo 4. Medio 5. Medio-alto 6. Alto; la clasificación en cualquiera de los seis estratos es una aproximación a la diferencia socioeconómica jerarquizada" [14], el $78 \%$ corresponde al estrato 1 y el $20 \%$ al 2. En el aspecto religioso, se encontró que la mayoría practica la religión católica, con un $57 \%$ y un $19 \%$ no práctica ninguna religión.

Tabla 1. Características sociodemográficas de mujeres con vih de una IPS en Cartagena.

\begin{tabular}{|c|c|c|}
\hline Características & & $\mathrm{N}(\%)$ \\
\hline \multirow[t]{5}{*}{ Estrato socioeconómico } & 1 & 78 \\
\hline & 2 & 20 \\
\hline & 3 & 1 \\
\hline & 5 & 1 \\
\hline & Total & 100 \\
\hline \multirow[t]{8}{*}{ Religión } & Adventista & 2 \\
\hline & Católica & 57 \\
\hline & Cristiana & 18 \\
\hline & Mormona & 2 \\
\hline & No practica & 19 \\
\hline & Pentecostal & 1 \\
\hline & Testigo de Jehová & 1 \\
\hline & Total & 100 \\
\hline \multirow[t]{3}{*}{ Procedencia } & Rural & 20 \\
\hline & Urbana & 80 \\
\hline & Total & 100 \\
\hline \multirow[t]{8}{*}{ Escolaridad } & Sin escolaridad & 1 \\
\hline & Primaria incompleta & 15 \\
\hline & Primaria completa & 9 \\
\hline & Secundaria incompleta & 37 \\
\hline & Secundaria completa & 18 \\
\hline & Técnico & 18 \\
\hline & Profesional & 2 \\
\hline & Total & 100 \\
\hline \multirow[t]{3}{*}{ Régimen de salud } & Subsidiado & 98 \\
\hline & Contributivo & 2 \\
\hline & Total & 100 \\
\hline
\end{tabular}

IPS: Institución prestadora de salud; vIH: Virus de inmunodeficiencia humana. 


\section{Tipología familiar según convivencia}

En relación con la tipología familiar, se encontró una distribución casi homogénea, comprendida entre la nuclear incompleta extensa (familia con un progenitor y otros parientes), el $27 \%$; la nuclear completa (padremadre e hijos), el $22 \%$, y la nuclear incompleta (familia con uno de los progenitores), el $23 \%$, mientras que el tipo de familia menos frecuente fue la unipersonal y la pareja sin hijos, ambas con $4 \%$ (véase Tabla 2).

\section{Dimensiones del apoyo social}

En cuanto al índice global de apoyo social, el $83 \%$ de las participantes percibió un apoyo social máximo (véase Tabla 3).

Tabla 2. Tipología familiar según convivencia, de mujeres con VIH de una IPS en Cartagena.

\begin{tabular}{lc}
\hline \multicolumn{1}{c}{ Tipología familiar según convivencia } & N (\%) \\
\hline Unipersonal (un integrante) & 4 \\
Nuclear completa (padre-madre e hijos) & 22 \\
Nuclear incompleta (familia con uno de los progenitores) & 23 \\
Parejas sin hijos & 4 \\
Nuclear incompleta extensa (familia con un progenitor y otros parientes) & 27 \\
Compuesta (familia con parientes y no parientes) & 6 \\
Extensa completa (familia nuclear con parientes) & 14 \\
Total & 100 \\
\hline
\end{tabular}

IPS: Institución prestadora de salud; VIH: Virus de inmunodeficiencia humana.

Tabla 3. Apoyo social percibido por mujeres con VIH de una IPS en Cartagena.

\begin{tabular}{lcccc}
\hline \multicolumn{1}{c}{ Dimensiones } & \multicolumn{4}{c}{ Apoyo social (Mos) } \\
\cline { 2 - 4 } & Máximo & Medio (DE) & Mínimo & Total \\
\hline $\begin{array}{l}\text { Índice global de } \\
\text { apoyo social }\end{array}$ & 83 & $17(22,0)$ & 0 & 100 \\
Apoyo emocional & 0 & $89(12,2)$ & 11 & 100 \\
Apoyo instrumental/ & 77 & $20(4,7)$ & 3 & 100 \\
material & 73 & $25(4,6)$ & 2 & 100 \\
Interacción social & 87 & $12(2,8)$ & 1 & 100 \\
positiva & & & & \\
Apoyo afectivo & & & & \\
\hline
\end{tabular}

DE: Desviación estándar.

Respecto al apoyo social por dimensiones, el apoyo emocional no registró en el rango máximo a ninguna participante; el $89 \%$ de ellas percibe el apoyo emocional en un rango medio.

Acerca del apoyo instrumental/material, referido a la asistencia económica, el apoyo en las actividades domésticas y otras, se reportó por un 77 \% la percepción de un apoyo máximo.

En las relaciones sociales de ocio y distracción, referido a tener personas disponibles para escuchar, apoyar y realizar actividades conjuntas de diversión, se halló que el $73 \%$ de las participantes percibe un apoyo máximo, y $25 \%$, medio.
Para el apoyo afectivo, que alude a contar con personas que le demuestren afecto y solidaridad, el $87 \%$ percibe un apoyo máximo, y el $1 \%$, apoyo mínimo.

\section{Relación entre el apoyo social y la tipología de familia según convivencia}

El índice global de apoyo social frente a los tipos de familia arrojó un puntaje promedio máximo, en donde la familia compuesta, conformada por parientes y no parientes, obtuvo un puntaje mayor, con un 101,2, a diferencia de la familia pareja sin hijos, con un puntaje menor de 74,5 (véase Tabla 4). 
Tabla 4. Puntajes promedios de las dimensiones según tipología familiar de mujeres con VIH de una IPS en Cartagena.

\begin{tabular}{|c|c|c|c|c|c|}
\hline \multirow[b]{2}{*}{$\begin{array}{l}\text { Tipología familiar según } \\
\text { convivencia }\end{array}$} & \multicolumn{5}{|c|}{ Dimensiones } \\
\hline & $\begin{array}{l}\text { Apoyo } \\
\text { emocional }\end{array}$ & $\begin{array}{c}\text { Apoyo } \\
\text { instrumental/ } \\
\text { material }\end{array}$ & $\begin{array}{c}\text { Interacción Social } \\
\text { positiva (ocio y } \\
\text { distracción) }\end{array}$ & $\begin{array}{l}\text { Apoyo } \\
\text { afectivo }\end{array}$ & $\begin{array}{l}\text { Índice } \\
\text { global }\end{array}$ \\
\hline Unipersonal (un integrante) & 38,3 & 16,0 & 15,0 & 12,0 & 81,3 \\
\hline $\begin{array}{l}\text { Nuclear completa (padre-madre e } \\
\text { hijos) }\end{array}$ & 34,1 & 15,7 & 15,0 & 13,0 & 77,8 \\
\hline $\begin{array}{l}\text { Nuclear incompleta (familia con } \\
\text { uno de los progenitores) }\end{array}$ & 40,8 & 16,0 & 15,2 & 13,1 & 85,0 \\
\hline Parejas sin hijos & 32,8 & 13,0 & 16,3 & 12,5 & 74,5 \\
\hline $\begin{array}{l}\text { Nuclear incompleta extensa (familia } \\
\text { con un progenitor y otros parientes) }\end{array}$ & 34,0 & 15,8 & 15,2 & 13,0 & 78,0 \\
\hline $\begin{array}{l}\text { Compuesta (familia con parientes y } \\
\text { no parientes) }\end{array}$ & 48,3 & 19,0 & 19,2 & 14,7 & 101,2 \\
\hline $\begin{array}{l}\text { Extensa completa (familia nuclear } \\
\text { con parientes) }\end{array}$ & 40,0 & 16,6 & 16,1 & 13,0 & 85,6 \\
\hline Pueba de Kruskal- Wallis & $0,024^{*}$ & 0,531 & 0,496 & 0,952 & 0,087 \\
\hline * Valor con diferencia significativa. & & & & & \\
\hline
\end{tabular}

Para la dimensión "apoyo emocional", se encontró un puntaje promedio máximo frente a todos los tipos de familia. La familia compuesta arrojó el mayor puntaje dentro del rango máximo, con un 48,3 , en contraste con el tipo de familia pareja sin hijos, el cual fue menor, con un 32,8 .

Acerca de la dimensión "apoyo instrumental/material", se obtuvo un puntaje promedio máximo respecto a todos los tipos de familia. Dentro de este rango máximo, el puntaje mayor fue para la familia compuesta, con un 19,0, frente al menor de la pareja sin hijos, con un 13,0.

En la dimensión "interacción social positiva (ocio y distracción)", los puntajes promedios obtenidos fueron máximos respecto a todos los tipos de familia. La compuesta arrojó el mayor puntaje dentro del rango máximo, con un 19,2, a diferencia de las familias nuclear completa y la unipersonal, con un puntaje de 15,0 cada una.

En cuanto a la dimensión "apoyo afectivo", se encontró un puntaje promedio máximo respecto a todos los tipos de familia. La compuesta arrojó el mayor puntaje dentro del rango máximo, con un 14,7, mientras que la familia unipersonal, un 12,0.
Finalmente, para la relación entre el apoyo social y la tipología familiar según convivencia, se encontró, de acuerdo con la prueba de Kruskal-Wallis, que los puntajes promedios respecto a las dimensiones "apoyo instrumental/material", "relaciones sociales de ocio y distracción", "apoyo afectivo" e "índice global de apoyo social" no mostraron una diferencia significativa, con valores de $0,531,0,496,0,952$ y 0,087 respectivamente. Sin embargo, fue en la dimensión "apoyo emocional" donde se encontró una diferencia significativa, con un 0,024 , es decir, hay variabilidad en la percepción del apoyo emocional según todos los tipos de familia, destacando a la familia compuesta, la cual obtuvo el mayor puntaje promedio.

Tras el análisis de varianza (ANOVA), se hizo la prueba post hoc Tukey al interior de la dimensión "apoyo emocional", a fin de explorar las diferencias entre grupos, encontrando diferencia significativa entre el tipo de familia compuesta y la nuclear completa ( $p$-valor 0,033 ) $\mathrm{y}$ entre las familias compuesta y nuclear incompleta extensa ( $p$-valor 0,033). Las diferencias de las medias fueron de 23,778 y 24,61, a favor del tipo de familia compuesta (véanse Tablas 5 a 8 ). 
Tabla 5. Estadísticos descriptivos de los tipos de familia de mujeres con VIH de una IPS en Cartagena.

\begin{tabular}{|c|c|c|c|c|c|c|c|}
\hline \multirow{2}{*}{\multicolumn{2}{|c|}{ Tipo de familia }} & \multicolumn{6}{|c|}{ Estadísticos descriptivos } \\
\hline & & $\mathrm{N}$ & Mínimo & Máximo & Media & Desviación & Varianza \\
\hline \multirow{2}{*}{ Unipersonal } & Total apoyo emocional & 4 & 11 & 60 & 42,00 & 21,463 & 460,667 \\
\hline & $\mathrm{N}$ válido (por lista) & 4 & & & & & \\
\hline \multirow{2}{*}{ Nuclear completa } & Total apoyo emocional & 22 & 15 & 60 & 38,27 & 13,163 & 173,255 \\
\hline & N válido (por lista) & 22 & & & & & \\
\hline \multirow{2}{*}{$\begin{array}{l}\text { Nuclear } \\
\text { incompleta }\end{array}$} & Total apoyo emocional & 23 & 15 & 100 & 49,39 & 20,367 & 414,794 \\
\hline & $\mathrm{N}$ válido (por lista) & 23 & & & & & \\
\hline \multirow{2}{*}{ Pareja sin hijos } & Total apoyo emocional & 4 & 22 & 46 & 36,50 & 11,705 & 137,000 \\
\hline & $\mathrm{N}$ válido (por lista) & 4 & & & & & \\
\hline \multirow{2}{*}{$\begin{array}{l}\text { Nuclear } \\
\text { incompleta } \\
\text { extensa }\end{array}$} & Total apoyo emocional & 27 & 10 & 70 & 38,56 & 15,624 & 244,103 \\
\hline & N válido (por lista) & 27 & & & & & \\
\hline \multirow{2}{*}{ Compuesta } & Total apoyo emocional & 6 & 46 & 100 & 62,33 & 19,725 & 389,067 \\
\hline & N válido (por lista) & 6 & & & & & \\
\hline \multirow{2}{*}{$\begin{array}{l}\text { Extensa } \\
\text { compuesta }\end{array}$} & Total apoyo emocional & 14 & 15 & 63 & 45,14 & 13,944 & 194,440 \\
\hline & $\mathrm{N}$ válido (por lista) & 14 & & & & & \\
\hline
\end{tabular}

Tabla 6. Resumen de prueba normal de Kolmogorov-Smirnov de los diferentes tipos de familias de mujeres con VIH usuarias de una IPS en Cartagena.

\begin{tabular}{|c|c|c|c|c|c|c|c|c|}
\hline \multirow{2}{*}{\multicolumn{2}{|c|}{ Estadísticos }} & \multicolumn{7}{|c|}{ Tipo de familia } \\
\hline & & \multirow{2}{*}{$\begin{array}{c}\text { Unipersonal } \\
4\end{array}$} & \multirow{2}{*}{$\begin{array}{c}\begin{array}{c}\text { Nuclear } \\
\text { completa }\end{array} \\
22\end{array}$} & \multirow{2}{*}{$\begin{array}{c}\begin{array}{c}\text { Nuclear } \\
\text { incompleta }\end{array} \\
23\end{array}$} & \multirow{2}{*}{$\begin{array}{l}\text { Pareja sin } \\
\text { hijos } \\
4\end{array}$} & \multirow{2}{*}{$\begin{array}{c}\begin{array}{c}\text { Nuclear } \\
\text { incompleta } \\
\text { extensa }\end{array} \\
27\end{array}$} & \multirow{2}{*}{$\begin{array}{c}\text { Compuesta } \\
6\end{array}$} & \multirow{2}{*}{$\begin{array}{c}\begin{array}{c}\text { Extensa } \\
\text { completa }\end{array} \\
14\end{array}$} \\
\hline $\mathrm{N}$ total & & & & & & & & \\
\hline \multirow{3}{*}{$\begin{array}{l}\text { Máximas } \\
\text { diferencias } \\
\text { extremas }\end{array}$} & Absoluta & 0,303 & 0,186 & 0,237 & 0,229 & 0,189 & 0,365 & 0,265 \\
\hline & Positivo & 0,255 & 0,124 & 0,154 & 0,202 & 0,163 & 0,301 & 0,166 \\
\hline & Negativo & $-0,303$ & $-0,186$ & $-0,237$ & $-0,229$ & $-0,189$ & $-0,365$ & $-0,265$ \\
\hline \multicolumn{2}{|c|}{ Estadístico de prueba } & 0,303 & 0,186 & 0,237 & 0,229 & 0,189 & 0,365 & 0,265 \\
\hline \multicolumn{2}{|c|}{$\begin{array}{l}\text { Significancia asintótica } \\
\text { (prueba bilateral) }^{\mathrm{a}}\end{array}$} & b & 0,047 & 0,002 & b & 0,015 & 0,012 & 0,008 \\
\hline
\end{tabular}

Tabla 7. Relación de los diferentes tipos de apoyo, con la técnica de ANOVA en mujeres con viH de una IPS en Cartagena.

\begin{tabular}{llccccc}
\hline \multicolumn{2}{c}{ Dimensiones del apoyo social } & $\begin{array}{c}\text { Suma de } \\
\text { cuadrados }\end{array}$ & gl & $\begin{array}{c}\text { Media } \\
\text { cuadrática }\end{array}$ & F & Significancia \\
\hline Total apoyo emocional & Entre grupos & 4429,234 & 6 & 738,206 & 2,705 & 0,018 \\
& Dentro de grupos & 25376,556 & 93 & 272,866 & & 0,635 \\
\cline { 2 - 7 } & Total & 29805,790 & 99 & & 0,719 & \\
\hline \multirow{2}{*}{\begin{tabular}{l} 
Total apoyo $\begin{array}{l}\text { instrumental/material } \\
\end{array}$ \\
\cline { 2 - 7 }
\end{tabular}} & Entre grupos & 97,044 & 6 & 16,174 & & \\
\cline { 2 - 7 } & Dentro de grupos & 2091,866 & 93 & 22,493 & & \\
& Total & 2188,910 & 99 & & &
\end{tabular}


Continuación tabla 7

\begin{tabular}{lllllll}
\hline \multicolumn{2}{c}{ Dimensiones del apoyo social } & \multicolumn{1}{c}{$\begin{array}{c}\text { Suma de } \\
\text { cuadrados }\end{array}$} & gl & $\begin{array}{c}\text { Media } \\
\text { cuadrática }\end{array}$ & F & Significancia \\
\hline \multirow{2}{*}{$\begin{array}{l}\text { Total relaciones ocio y y } \\
\text { distracción }\end{array}$} & Entre grupos & 99,403 & 6 & 16,567 & 0,784 & 0,585 \\
& Dentro de grupos & 1965,437 & 93 & 21,134 & & \\
\cline { 2 - 7 } & Total & 2064,840 & 99 & & 0,427 & 0,859 \\
\hline Total apoyo afectivo & Entre grupos & 21,396 & 6 & 3,566 & & \\
& Dentro de grupos & 777,114 & 93 & 8,356 & & \\
\cline { 2 - 7 } & Total & 798,510 & 99 & & & \\
\end{tabular}

F: Prueba F o estadística de prueba; gl: grados de libertad

Tabla 8. Comparación del apoyo emocional entre los tipos de familia de mujeres con VIH de una IPS en Cartagena, método HSD Tukey (Honestly-significant-difference de Tukey)

\begin{tabular}{|c|c|c|c|c|c|c|}
\hline \multirow{2}{*}{$\begin{array}{l}\text { (I) Tipo } \\
\text { familia }\end{array}$} & \multirow{2}{*}{ (J) Tipos familia } & \multirow{2}{*}{$\begin{array}{c}\text { Diferencia de } \\
\text { medias (I-J) }\end{array}$} & \multirow{2}{*}{$\begin{array}{l}\text { Error } \\
\text { estándar }\end{array}$} & \multirow{2}{*}{ Significancia } & \multicolumn{2}{|c|}{$\begin{array}{c}\text { Intervalo de confianza al } \\
95 \%\end{array}$} \\
\hline & & & & & $\begin{array}{l}\text { Límite } \\
\text { inferior }\end{array}$ & $\begin{array}{l}\text { Límite } \\
\text { superior }\end{array}$ \\
\hline \multirow{6}{*}{ Unipersonal } & Nuclear completa & 3,727 & 8,979 & 1,000 & $-23,33$ & 30,79 \\
\hline & Nuclear incompleta & $-7,391$ & 8,949 & ,982 & $-34,36$ & 19,58 \\
\hline & Pareja sin hijos & 5,500 & 11,680 & ,999 & $-29,70$ & 40,70 \\
\hline & $\begin{array}{l}\text { Nuclear incompleta } \\
\text { extensa }\end{array}$ & 3,444 & 8,850 & 1,000 & $-23,23$ & 30,12 \\
\hline & Compuesta & $-20,333$ & 10,663 & ,481 & $-52,47$ & 11,80 \\
\hline & Extensa completa & $-3,143$ & 9,365 & 1,000 & $-31,37$ & 25,08 \\
\hline \multirow{6}{*}{$\begin{array}{l}\text { Nuclear } \\
\text { completa }\end{array}$} & Unipersonal & $-3,727$ & 8,979 & 1,000 & $-30,79$ & 23,33 \\
\hline & Nuclear incompleta & $-11,119$ & 4,926 & ,276 & $-25,97$ & 3,73 \\
\hline & Pareja sin hijos & 1,773 & 8,979 & 1,000 & $-25,29$ & 28,83 \\
\hline & $\begin{array}{l}\text { Nuclear incompleta } \\
\text { extensa }\end{array}$ & $-0,283$ & 4,744 & 1,000 & $-14,58$ & 14,02 \\
\hline & Compuesta & $-24,061^{*}$ & 7,608 & 0,033 & $-46,99$ & $-1,13$ \\
\hline & Extensa completa & $-6,870$ & 5,647 & 0,886 & $-23,89$ & 10,15 \\
\hline \multirow{6}{*}{$\begin{array}{l}\text { Nuclear } \\
\text { incompleta }\end{array}$} & Unipersonal & 7,391 & 8,949 & 0,982 & $-19,58$ & 34,36 \\
\hline & Nuclear completa & 11,119 & 4,926 & 0,276 & $-3,73$ & 25,97 \\
\hline & Pareja sin hijos & 12,891 & 8,949 & 0,778 & $-14,08$ & 39,86 \\
\hline & $\begin{array}{l}\text { Nuclear incompleta } \\
\text { extensa }\end{array}$ & 10,836 & 4,687 & 0,250 & $-3,29$ & 24,96 \\
\hline & Compuesta & $-12,942$ & 7,572 & 0,612 & $-35,76$ & 9,88 \\
\hline & Extensa completa & 4,248 & 5,599 & 0,988 & $-12,63$ & 21,12 \\
\hline \multirow{6}{*}{ Pareja sin hijos } & Unipersonal & $-5,500$ & 11,680 & 0,999 & $-40,70$ & 29,70 \\
\hline & Nuclear completa & $-1,773$ & 8,979 & 1,000 & $-28,83$ & 25,29 \\
\hline & Nuclear incompleta & $-12,891$ & 8,949 & 0,778 & $-39,86$ & 14,08 \\
\hline & $\begin{array}{l}\text { Nuclear incompleta } \\
\text { extensa }\end{array}$ & $-2,056$ & 8,850 & 1,000 & $-28,73$ & 24,62 \\
\hline & Compuesta & $-25,833$ & 10,663 & 0,201 & $-57,97$ & 6,30 \\
\hline & Extensa completa & $-8,643$ & 9,365 & 0,968 & $-36,87$ & 19,58 \\
\hline
\end{tabular}




\begin{tabular}{|c|c|c|c|c|c|c|}
\hline \multirow{2}{*}{$\begin{array}{l}\text { (I) Tipo } \\
\text { familia }\end{array}$} & \multirow{2}{*}{ (J) Tipos familia } & \multirow{2}{*}{$\begin{array}{c}\text { Diferencia de } \\
\text { medias (I-J) }\end{array}$} & \multirow{2}{*}{$\begin{array}{l}\text { Error } \\
\text { estándar }\end{array}$} & \multirow{2}{*}{ Significancia } & \multicolumn{2}{|c|}{$\begin{array}{c}\text { Intervalo de confianza al } \\
95 \%\end{array}$} \\
\hline & & & & & $\begin{array}{l}\text { Límite } \\
\text { inferior }\end{array}$ & $\begin{array}{l}\text { Límite } \\
\text { superior }\end{array}$ \\
\hline \multirow{6}{*}{$\begin{array}{l}\text { Nuclear } \\
\text { incompleta } \\
\text { extensa }\end{array}$} & Unipersonal & $-3,444$ & 8,850 & 1,000 & $-30,12$ & 23,23 \\
\hline & Nuclear completa & 0,283 & 4,744 & 1,000 & $-14,02$ & 14,58 \\
\hline & Nuclear incompleta & $-10,836$ & 4,687 & 0,250 & $-24,96$ & 3,29 \\
\hline & Pareja sin hijos & 2,056 & 8,850 & 1,000 & $-24,62$ & 28,73 \\
\hline & Compuesta & $-23,778^{*}$ & 7,455 & 0,031 & $-46,25$ & $-1,31$ \\
\hline & Extensa completa & $-6,587$ & 5,440 & 0,888 & $-22,98$ & 9,81 \\
\hline \multirow[t]{6}{*}{ Compuesta } & Unipersonal & 20,333 & 10,663 & 0,481 & $-11,80$ & 52,47 \\
\hline & Nuclear completa & $24,061^{*}$ & 7,608 & 0,033 & 1,13 & 46,99 \\
\hline & Nuclear incompleta & 12,942 & 7,572 & 0,612 & $-9,88$ & 35,76 \\
\hline & Pareja sin hijos & 25,833 & 10,663 & 0,201 & $-6,30$ & 57,97 \\
\hline & $\begin{array}{l}\text { Nuclear incompleta } \\
\text { extensa }\end{array}$ & $23,778^{\star}$ & 7,455 & 0,031 & 1,31 & 46,25 \\
\hline & Extensa completa & 17,190 & 8,060 & 0,343 & $-7,10$ & 41,48 \\
\hline \multirow{6}{*}{$\begin{array}{l}\text { Extensa } \\
\text { completa }\end{array}$} & Unipersonal & 3,143 & 9,365 & 1,000 & $-25,08$ & 31,37 \\
\hline & Nuclear completa & 6,870 & 5,647 & 0,886 & $-10,15$ & 23,89 \\
\hline & Nuclear incompleta & $-4,248$ & 5,599 & 0,988 & $-21,12$ & 12,63 \\
\hline & Pareja sin hijos & 8,643 & 9,365 & 0,968 & $-19,58$ & 36,87 \\
\hline & $\begin{array}{l}\text { Nuclear incompleta } \\
\text { extensa }\end{array}$ & 6,587 & 5,440 & 0,888 & $-9,81$ & 22,98 \\
\hline & Compuesta & $-17,190$ & 8,060 & 0,343 & $-41,48$ & 7,10 \\
\hline
\end{tabular}

* La diferencia de medias es significativa en el nivel 0,05 .

\section{Discusión}

Respecto a las características sociodemográficas de las participantes del estudio, se encontró que el promedio de edad fue de 40 años. Este resultado tiene similitud a lo hallado en un trabajo realizado en Cartagena [15], donde el promedio fue de 39 años. En México, otra investigación arrojó un promedio de edad de 32 años [16]. Así, las edades de las mujeres oscilan entre 30 y 40 años. Esta década en la trayectoria vital de las mujeres se caracteriza por la actividad laboral para generar ingresos a sus hogares y la finalización de su etapa reproductiva, lo cual sugiere que convivir con VIH en este periodo puede ser de gran impacto en sus vidas.

En relación con el lugar de procedencia, en este estudio, la mayoría de las participantes pertenece a la zona urbana. Esto es similar a lo que se encontró en un trabajo en México [16], en donde era del $88 \%$, y contrasta con otra investigación llevada a cabo en Colombia, en donde se halló que la procedencia era equitativa [15]. Una investigación en Perú indica que existe una asociación positiva entre proceder de zonas urbanas y poseer mejor nivel de conocimientos y actitudes adecuada sobre VIH [17].

Otro aspecto a analizar es la escolaridad de las participantes. En este estudio predominó la secundaria incompleta, aspecto que no difiere a otras investigaciones, por ejemplo, una investigación realizada en Brasil [18], con una población de mujeres seropositivas, donde se halló un bajo nivel de escolaridad, con menos de 8 años de estudio. En Perú, un trabajo arrojó que el $57 \%$ de las mujeres había cursado hasta secundaria incompleta [19]. Frente a este hecho, un estudió en Perú determinó que la escolaridad puede ser un factor protector ante el VIH, es decir, a mayor nivel educativo, habrá más control de la enfermedad, mejores actitudes y prácticas apropiadas [17].

En cuanto al estrato socioeconómico, en esta investigación se encuentra que la mayoría de las mujeres participantes pertenecen al estrato 1. Este resultado es semejante a lo hallado en un trabajo realizado en Cartagena, en donde un gran porcentaje de la población de estudio pertenece al mismo nivel socioeconómico [15], 
y a otro estudio de México, donde el $37 \%$ de la población estaba en situación de pobreza extrema [16]; por lo tanto, la pobreza viene siendo una común dominante en las mujeres seropositivas.

El factor socioeconómico puede estar vinculado con los conocimientos y las prácticas que indican que a mayor nivel socioeconómico, habrá más conocimiento hacia actitudes adecuadas y prácticas sexuales seguras [17]. Otro estudio encontró una disminución de la frecuencia de actitudes positivas en tanto se disminuye el nivel de riqueza, lo que se manifiesta en actitudes discriminatorias [20].

Es frecuente hallar esta relación entre el diagnóstico de VIH y familias con algún grado de pobreza, como lo evidencia una publicación en Colombia, donde señala que las mujeres en familias pobres deben, además de asumir el rol de madres y cuidadoras, contribuir con la proveeduría económica, a través de su trabajo fuera del hogar, el cual se desarrolla en la informalidad en la mayoría de las veces [21].

Por otro lado, acerca de la tipología familiar, en este estudio se encontró que la mayoría de las mujeres pertenece a la familia de tipo nuclear incompleta extensa, es decir, conviven con el padre o la madre, y otros parientes, siendo estos abuelos, tíos o primos, en contraste con un trabajo en México [22] con mujeres VIH, en donde la familia que más porcentaje tuvo fue la de tipo nuclear, en un $45 \%$. Esto podría deberse a que, en Colombia, el tipo de familia nuclear ha venido disminuyendo su proporción en la tipología familiar, mientras la ha ganado el tipo de familia conformado a partir de solo uno de los padres, resultado de la creciente desintegración de las uniones/matrimonios, por divorcios o separaciones [23].

Ahora bien, las mujeres, históricamente, han ocupado roles que se han "naturalizado genéricamente" y en este sentido sus vidas trascienden aún sobre su propia salud. Así, aun a pesar de su condición de ser portadora de VIH o de cuidadora de algún familiar con esta condición, deben continuar afrontando situaciones de crisis al interior de sus familias, el abandono de sus parejas y las complejas relaciones entre sus miembros, como lo evidenció una investigación en Colombia sobre jefas de hogar con VIH/SIDA [21].

Respecto a la percepción de apoyo social, la cual es una variable mediadora fundamental en el proceso de estrés y es considerado un elemento de resiliencia [24], en las participantes del presente estudio obtuvo un nivel máximo, lo que podría deberse al aumento de la red de apoyo cercana, la asimilación del diagnóstico, el fácil acceso a los servicios de salud, así como la asistencia a los programas de la IPS. El mismo comportamiento ocurre en una investigación en México [25], donde el apoyo social era positivo en más del $50 \%$ de los pacientes, y suponen que a mayor apoyo es mayor la adherencia te- rapéutica. De igual manera, en un trabajo en Brasil [26] hallaron que la mayoría de los participantes tuvo un apoyo social satisfactorio total y lo relacionaron con características como la alta escolaridad, tener un trabajo y convivir con los miembros de la familia. El apoyo social permite a las personas de una familia sentirse integrada e importante; percibirse apoyada le permite canalizar sus emociones. Entre más alto es el índice de esta percepción, mayor será la probabilidad de que incremente su estado de salud física y emocional, disminuyendo la aparición de emociones disfóricas [9].

En la dimensión "apoyo emocional", que se refiere a la manifestación de diferentes emociones principalmente de manera verbal, en la investigación que aquí se presenta no se encontró una percepción máxima por parte de las participantes; sin embargo, la mayoría percibe un apoyo medio, condición que si bien no es negativa, sí muestra algún grado de debilidad en la necesidad de recibir y percibir este tipo de apoyo. Este panorama difiere a lo encontrado en México utilizando el mismo instrumento, donde más del $80 \%$ de los participantes encuestados percibieron un apoyo emocional máximo [25], mientras que en otro estudio efectuado en Cuba [27] prevaleció la necesidad de apoyo emocional en el $81 \%$ de los participantes.

En la dimensión "apoyo instrumental/material", las participantes del estudio, en su mayoría, perciben un apoyo máximo, lo que indica que cuentan o podrían contar con personas cercanas para suplir necesidades económicas básicas, en la ayuda con las tareas cotidianas del hogar, y soporte en otros ámbitos, como el laboral, entre otros, situación que tiene implicaciones positivas en la calidad de vida de las personas.

Un trabajo en Brasil encontró que los pacientes que vivían solos tuvieron menos apoyo social instrumental en comparación con aquellos que convivían junto a otras personas, lo cual podría ocasionar un impacto negativo sobre la salud, las actividades diarias y en la ayuda financiera [26]. En una revisión de la literatura sobre determinantes de la calidad de vida en personas que conviven con VIH, realizada en Bélgica, se halló que el apoyo social a su vez ofrece un mejor efecto predictivo para las condiciones de salud y de calidad de vida. El apoyo emocional se comporta como amortiguador del estrés, pues entre más alto sea aquel, mejora el impacto positivo en las personas que conviven con VIH. Sin embargo, existe diferencia en relación con el apoyo social tangible, equivalente a lo que se concibe como apoyo instrumental, donde se encontró que el mayor índice del mismo genera en las personas una autopercepción de mayor enfermedad y sus indicadores de calidad de vida estaban más bajos, lo cual puede estar relacionado con pérdida de independencia [28]. Esta situación es interpretada por otros autores como el resultado de la inferencia de 
situaciones de salud mental, como depresión, capacidad deficiente de afrontamiento, así como disminución de ingresos económicos por pérdida laboral [24].

En la dimensión "interacción social positiva (ocio y distracción)", que alude a disponer de un círculo social que escuche, aconseje y acompañe en las actividades de distracción y esparcimiento, gran parte de las participantes de este trabajo perciben un apoyo máximo, semejante a los resultados de un estudio en México [25]. Sin embargo, es posible encontrar situaciones contrarias: las personas perciben negativamente el apoyo por parte de los contactos cercanos, posiciones que van a depender de la solidez de los vínculos afectivos y la relevancia que les confieren las otras personas a los estigmas existentes en torno al diagnóstico [29]. En una investigación en Cartagena se afirma que la red social es efectiva no solo por la existencia de un vínculo, sino también por la habilidad, la comprensión, el conocimiento y la motivación que tienen los involucrados para proveer soporte a la persona que necesita del apoyo [30].

En la dimensión "afecto", relacionada con las expresiones de cariño, aquellas que tienen la capacidad de hacer sentirlas cercanas, unidas y conectadas con los pares y familiares, fueron percibidas por la mayoría de las mujeres del presente estudio en un nivel de apoyo máximo, similar a lo hallado en dos estudios en México [25,31]. De igual manera, otra investigación en Chile [32] arrojó que las mujeres que poseían una red de vínculos afectivos más amplia, reportaron sentir mayor apoyo afectivo, siendo el apoyo un poderoso determinante en el proceso de la adherencia al tratamiento antirretroviral.

Por otra parte, respecto a los datos obtenidos en el presente estudio, se evidencia un índice global de apoyo social máximo frente a la tipología familiar según convivencia, lo que permite determinar que no existe una relación directa entre el apoyo social percibido y el tipo de familia de las mujeres encuestadas, es decir, la estructura familiar no parece definir el nivel de apoyo percibido por una mujer seropositiva. Sin embargo, cabe resaltar que la mayoría de las encuestadas refería no haber informado su diagnóstico final a todos sus familiares, amigos o a su anterior pareja. Esto puede deberse a que las mujeres lo utilizan como método de protección ante un posible rechazo, situación que pudo influir en los resultados de la presente investigación.

Este supuesto se asemeja a los resultados de un estudio llevado a cabo en México [33], donde se señala que la mujer puede callar su condición de ser seropositiva al VIH por miedo a la discriminación y la estigmatización, siendo selectivas a la hora de revelar su diagnóstico. Esta situación no es alejada de la realidad, puesto que un trabajo en Colombia evidenció que una condición de mayor vulnerabilidad para las mujeres que conviven con $\mathrm{VIH}$ es la violencia basada en género que experimentan en mayores índices y en las distintas formas de abuso, estando más proclive a padecerla cuando dan a conocer su diagnóstico de seropositividad, por lo que suelen optar, como forma de autoprotección, por no revelar su resultado [34]. No obstante, en otras situaciones, la familia, a pesar de conocer el diagnóstico, sigue siendo ese espacio acogedor y menos discriminatorio, como lo sustenta un estudio de tipo cualitativo realizado en México, en donde aquella sigue brindando apoyo emocional y acompañamiento al miembro afectado, para que así asimile mejor su diagnóstico [22].

Por otro lado, en la dimensión "apoyo emocional", a pesar de arrojar un índice máximo, se encontró una diferencia significativa en relación con el tipo de familia, siendo más notoria en la familia compuesta, con un índice más alto en comparación con la de la pareja sin hijos. En otras palabras, las mujeres que pertenecen a una familia compuesta perciben más apoyo que las mujeres que viven solamente con su pareja. Esto podría atribuirse a que a mayor cantidad de personas con las que convive, más probabilidad de percibir apoyo.

La diferencia encontrada entre los tipos familiares en el apoyo emocional se observó entre los tipos nuclear completa y compuesta, nuclear incompleta extensa y la compuesta. Esta diferencia significativa puede deberse a que la familia compuesta excede a los otros tipos en su capacidad de superar los vínculos sanguíneos y reproductivos entre sus integrantes, lo cual puede constituirse más en una afinidad para brindarse apoyo emocional, congruente con lo que expresan Martínez, Estévez e Inglés [35] sobre las formas de apoyo en los tipos de familia.

Finalmente, la población de mujeres participantes en el presente estudio se caracteriza por pertenecer al ciclo vital adultas maduras, procedentes en su mayoría de la ciudad de Cartagena, con niveles educativos bajos y escasos recursos económicos, y en su mayoría conviven con algún progenitor y otros parientes, es decir, en una familia nuclear incompleta extensa.

En cuanto al apoyo social, las participantes perciben de sus contactos más cercanos un apoyo máximo, indicando que estas mujeres cuentan con redes de apoyo sólidas, lo que favorece positivamente el afrontamiento de la enfermedad.

De la misma manera, percibieron un buen apoyo social en relación con la tipología familiar, es decir, la manera en que está estructurada la familia no parece ser un factor determinante en cómo ellas perciben el apoyo.

No obstante, en el apoyo emocional se encontró una diferencia significativa, siendo la familia compuesta, entre los otros tipos de familia, la que mostró un mayor índice.

Se sugiere profundizar este estudio con un abordaje desde un enfoque cualitativo, e indagar sobre otros factores que pueden influir en la percepción de apoyo social, como, por ejemplo, la funcionalidad familiar. 
A la luz de los aportes en salud pública, se motiva a los profesionales y a las instituciones que prestan una atención integral a esta población a seguir utilizando estrategias que favorezcan el fortalecimiento de acciones con enfoque biopsicosocial que ofrezcan herramientas a las pacientes para afrontar su diagnóstico, y hacer partícipe directo a la familia. Se sugiere también fomentar grupos de apoyo entre pares, para que compartan experiencias, el afrontamiento de la enfermedad y mejoren la adherencia a los programas.

\section{Conflicto de interés}

Las autoras manifiestan que no tienen ningún conflicto que declarar.

\section{Fuentes de financiación}

Esta investigación se llevó a cabo con recursos propios.

\section{Declaración de responsabilidad}

Los puntos de vista tratados en el presente artículo son de responsabilidad de las autoras y no de la Universidad de Cartagena, ni de la Revista, ni la IPS donde se realizó el estudio.

\section{Agradecimientos}

Agradecemos la participación y el acompañamiento del profesor Luis Alvis en el procesamiento estadístico y de la profesora Katy Escobar, epidemióloga, quien apoyó el análisis de significancias estadísticas.

\section{Declaración de contribución por autores}

Las investigadoras suscritas certificamos ser responsables de todos los aspectos del trabajo presentado y estamos en disposición de responder por cualquier parte o la integridad del mismo. De manera específica, realizamos las siguientes contribuciones:

Esther Polo Payares: concepción del tema de investigación; planeación, gestión, auditoría proceso de recolección de información, revisión y análisis documental y de resultados, y redacción del documento. Aprobación final del documento.

Adriana Ardila Hernández y Dannis Ibáñez Polo: planeación, recolección, digitación y procesamiento de la información; análisis, revisión y análisis documental; redacción del documento.

\section{Referencias}

1. Organización de las Naciones Unidas. Estimaciones del VIH y SIDA. Hoja informativa [internet]; 2018 [citado 2020 jun. 1]. Disponible en: https://www.unaids.org/es/regionscountries/countries/ colombia

2. Departamento Administrativo Distrital de Salud. Comportamiento epidemiológico de VIH/SIDA y muerte por SIDA. Semana epidemiológica número 52 - 2017 [internet]; 2017 [citado 2018 mar. 1]. Disponible en: https://www.dadiscartagena.gov.co/images/docs/saludpublica/vigilancia/boletines/2017/vih_sida_sem_52_2017.pdf

3. Ministerio de Salud y Protección Social, Ministerio de Hacienda y Crédito Público. Fondo Colombiano de Enfermedades de Alto Costo [internet]; s. f. [citado 2020 sep. 20]. Disponible en: https:// cuentadealtocosto.org/site/vih/

4. Moral J, Segovia M. Discriminación en el trabajo y el vecindario hacia las mujeres que viven con VIH y su relación con la depresión y la ira. Ciencia Ergo Sum [internet]. 2014 [citado 2018 mar. 1]; 22(3):204-14. Disponible en: https://www.redalyc.org/ pdf/104/10441539004.pdf

5. Caballero N, Rodríguez C, et al. Comparison of levels of anxiety and depression between women and men living with HIV of a Mexico City clinic. Salud Mental. 2017;40(1):15-22. Dor: https:// doi.org/10.17711/SM.0185-3325.2017.003

6. Fernández D. Doblemente discriminadas. Situación de las mujeres con VIH/SIDA en Venezuela. Cuestiones de género: de la igualdad y la diferencia [internet]. 2015 [citado 2018 mar. 1]; (10):225-48. Disponible en: http://revpubli.unileon.es/ojs/index.php/cuestionesdegenero/article/view/1432/1390

7. Bolaños M. Implicaciones éticas, legales y sociales del diagnóstico de VIH/SIDa en la mujer. Rev. Cub. Salud Pública [internet]. 2013 [citado 2018 mar. 2]; 39(1):124-34. Disponible en: http:// scielo.sld.cu/pdf/rcsp/v39n1/spu11113.pdf

8. Arteaga A, Cogollo R, Muñoz D. Apoyo social y control metabólico en la diabetes mellitus tipo 2. Revi Cuid. 2017;8(2):16681676. DoI: http://dx.doi.org/10.15649/cuidarte.v8i2.405

9. Romero E, Amador C, Alvis L. Apoyo social y calidad de vida en pacientes con VIH/SIDA, residentes en Montería. Colombia. Revista Ciencias Biomédicas [internet]. 2010 [citado 2018 mar. 6]; 1(2):173-9. Disponible en: http://repositorio.unicartagena.edu. co/bitstream/handle/11227/6241/Apoyo\%20social\%20y\%20calidad $\% 20$ de $\% 20$ vida $\% 20$ en $\% 20$ pacientes $\% 20$ con $\% 20$ VIH $\% 20$ SIDA,\%20residentes\%20en\%20Monter\%EDa\%20Colombia.pdf ;jsessionid=1B6DD516281D7E22A8F949ED5B37A4CE?seque nce $=1$

10. Agudelo Bedoya M, Vélez M. Soporte social y familiar: experiencias con familias de pacientes atendidos en una clínica universitaria. Revista Palobra. 2016;16(16):82-97. Dor: https://doi. org/10.32997/2346-2884-vol.16-num.16-2016-1428

11. Londoño N, Rogers H, Castilla J, et al. Validación en Colombia del cuestionario mos de apoyo social. Int J Psychol Res [internet] 2012 [citado 2018 mar. 9]; 5(1):142-50. Disponible en: https:// www.redalyc.org/pdf/2990/299023539016.pdf

12. Ministerio de Salud. Resolución número 8430 de 1993- Normas científicas, técnicas y administrativas para la investigación en salud [internet]; [citado 2020 sep. 20]. Disponible en: https://www. minsalud.gov.co/sites/rid/Lists/BibliotecaDigital/RIDE/DE/DIJ/ RESOLUCION-8430-DE-1993.PDF.

13. Colombia, Congreso de la República. Ley 266, por la cual se reglamenta la profesión de enfermería en Colombia y se dictan otras disposiciones (1996 ene. 25). 
14. DANE. Estratos socioeconómicos. Preguntas Frecuentes [internet]; s. f. [citado 2020 sep. 21]. Disponible en: https://www.dane.gov.co/ files/geoestadistica/Preguntas_frecuentes_estratificacion.pdf

15. Montalvo A, Herrera A. SIDA: sufrimiento de las personas con la enfermedad, Cartagena. Av. Enferm. 2015;33(1):85-93. DoI: http://dx.doi.org/10.15446/av.enferm.v33n1.48117

16. Flores M, Laureano J, Mejía M. Significado y percepción frente al VIH/SIDA en mujeres rurales parejas de migrantes, Jalisco, México. Rev. Costarric Salud Pública [internet]. 2015 [citado 2018 mar. 13]; 24(2):115-25. Disponible en: https://www.scielo.sa.cr/ $\mathrm{pdf} / \mathrm{rcsp} / \mathrm{v} 24 \mathrm{n} 2 / 1409-1429-\mathrm{rcsp}-24-02-00115 . \mathrm{pdf}$

17. Pernaz G, Cárcamo C. Conocimientos, actitudes y prácticas de la mujer peruana sobre la infección por VIH/SIDA. Rev. Perú. Med. Exp. Salud Pública [internet]. 2015 [citado 2018 abr. 5]; 32(4):667-72. Disponible en: http://www.scielo.org.pe/pdf/rins/ v32n4/a06v32n4.pdf

18. Cassamassimo M, García C, Do Rosário L. Vulnerabilidad de mujeres viviendo con VIH/SIDA. Rev. Latino-Am. Enfermagem. 2014; 22(1). DOI: https://doi.org/10.1590/0104-1169.2837.2377

19. Reyes M. Factores asociados a la no realización del tamizaje para VIH durante la gestación en gestantes atendidas en establecimientos del Ministerio de Salud [tesis de maestría]. [Lima]: Universidad Nacional Mayor de San Marcos [internet]; 2014 [citado 2018 oct. 5]. Disponible en: https://core.ac.uk/reader/323348290

20. Becerra V, Chunga N, Palomino C, et al. Asociación entre el conocimiento de las mujeres peruanas acerca del VIH y sus actitudes frente a personas infectadas. Rev Peru Epidemiol [internet]. 2012 [citado 2018 oct. 10]; 16(3):1-8. Disponible en: https://www.redalyc.org/articulo.oa?id=203125431007

21. Hoyos P, Duarte C. Roles y desafíos de mujeres jefas de hogar con VIH/SIDA. Rev. Salud Pública. 2016;18(4):554-67. DoI: http:// dx.doi.org/10.15446/rsap.v18n4.42096

22. Chapa A, Almanza A, Gómez L. Narrativas de los familiares como cuidadores primarios de pacientes con infección por virus de inmunodefiencia humana (VIH). En: Virseda JA, Bezanilla JM (coordinadores), Enfermedad y familia. Vol. 1. Toluca: Universidad Autónoma del Estado de México [internet]; 2014 [citado 2018 oct. 11]. pp. 131-44. Disponible en: https://www.facico-uaemex. $\mathrm{mx} / 2018-2022 /$ descargas/libros-electronicos/enfermedadyfamiliaI.pdf\#page $=132$

23. Departamento Nacional de Planeación. Tipologías de familias en Colombia: Evolución 1993-2014. Documento de trabajo núm. 2016-1. [internet]; 2015 [citado 2018 oct. 11]. Disponible en: https://observatoriodefamilia.dnp.gov.co/Documents/Documentos\%20de\%20trabajo/D3-tipologias-evolucion_dic3-(1).pdf

24. Moreno J, Barragán A, Martínez M, et al. Calidad de vida y percepción de apoyo social en personas con HIV en Bogotá, Colombia. Biomédica. 2018;38(4):577-85. DoI: https://doi.org/10.7705/ biomedica.v38i4.3819

25. Díaz R, Elizarrarás J, Salinas C, et al. Apoyo social y adherencia terapéutica en pacientes portadores de VIH en el Hospital General de Zona No. 1 del Instituto Mexicano del Seguro Social de Oaxaca. Avances en Ciencia, Salud y Medicina [internet]. 2018 [citado 2018 oct. 15]; 5(1):10-16. Disponible en: http://www.salud.oaxaca.gob.mx/wp-content/uploads/2018/07/Acs-181-02i.pdf

26. Da Frota V, Citó S, De Souza P, et al. Social support of people with HIV/AIDS: The social determinants of health model. Rev. Bras. Enferm. 2017;71(Supl. 1):625-30. Dor: https://doi.org/10.1590/00347167-2017-0346

27. Vilató L, Martín L, Pérez I. Adherencia terapéutica y apoyo social percibido en personas que viven con VIH/SIDA. Rev Cubana Salud Pública [internet]. 2015 [citado 2018 nov. 11]; 41(4):620-30. Disponible en: http://scielo.sld.cu/scielo.php?script=sci_arttext\&pid $=$ S0864-34662015000400005

28. Degroote S, Vogelaers D, Vandijck D. What determines healthrelated quality of life among people living with HIV: An updated review of the literature Arch Public Health. 2014;72(40). DOI: https://doi.org/10.1186/2049-3258-72-40

29. Bran L, Palacios L, et al. Cambios percibidos en la vida cotidiana por adultos que viven con VIH. Convergencia [internet]. 2018 [citado 2019 feb. 7]; (76):57-74. http://www.scielo.org.mx/scielo. php?script=sci_abstract\&pid=S1405-14352018000100057\&lng= es\&nrm=iso

30. Beleño S. Fortalecimiento de habilidades y capacidades de emprendimiento: generador de inclusión laboral a mujeres cabeza de hogar que conviven con VIH y SIDA [trabajo de grado]. [Cartagena]: Universidad de Cartagena [internet]; 2018 [citado 2019 may. 7]. Disponible en: http://repositorio.unicartagena.edu.co/ bitstream/handle/11227/6439/FORTALECIMIENTO\%20DE\%20 HABILIDADES\%20Y\%20CAPACIDADES\%20DE\%20EMPRENDIMIENTO_\%20GENERADOR\%20DE\%20INCLUSION\%20LABORAL\%20A\%20MUJERES\%20CABEZA\%20 DE\%20HOGAR\%20 1.pdf? sequence=1\&isAllowed=y

31. Mosqueda D, Reyes G, Montuy Y, et al. Apoyo social en personas que viven con VIH. Salud, Educación, Sociedad y Economía en la Frontera Sur de México [internet]; 2017 [citado 2019 may. 7]. Disponible en: http://www.sidastudi.org/resources/inmagic-img/ DD46905.pdf

32. Belmar J, Stuardo V. Adherencia al tratamiento anti-retroviral para el VIH/sIDA. Revi Chil Infectol. 2017; 34(4):352-8. DOI: http:// dx.doi.org/10.4067/s0716-10182017000400352

33. Moral J, Segovia M. Discriminación en la familia a mujeres que viven con VIH. Psicogente [internet]. 2015 [citado 2020 jun. 1]; 18(33):89-103. Disponible en: http://www.scielo.org.co/pdf/psi$\mathrm{co} / \mathrm{v} 18 \mathrm{n} 33 / \mathrm{v} 18 \mathrm{n} 33 \mathrm{a} 08 . \mathrm{pdf}$

34. Arévalo L. Violencia de pareja en la mujer que vive con VIH. Rev. Colomb. Enferm. 2018;16(13):52-63. DOI: http://dx.doi. org/10.18270/rce.v16i13.2304

35. Martínez M, Estévez E, Inglés C. Diversidad familiar y ajuste psicosocial en la sociedad actual. Rev. Psicología.com [internet]. 2013 [citado 2020 jun. 3]; 17(6):1-22. Disponible en: https:// www.uv.es/lisis/estevez/art13/psicologia-com-art13.pdf 